
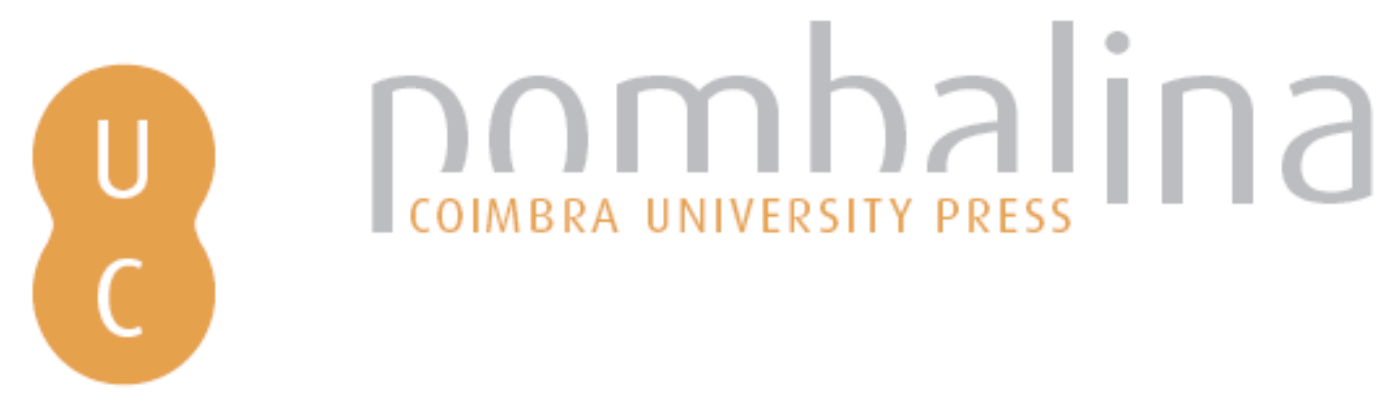

\title{
Analysis of the jump fire produced by the interaction of two oblique fire fronts: Comparison between laboratory and field cases
}

\author{
Autor(es): $\quad$ Raposo, Jorge; Viegas, Domingos X.; Xie, Xiaodong; Almeida, Miguel; \\ Naian, Liu \\ Publicado por: Imprensa da Universidade de Coimbra \\ URL \\ persistente: URI:http://hdl.handle.net/10316.2/34027 \\ DOI: DOI:http://dx.doi.org/10.14195/978-989-26-0884-6_8 \\ Accessed : $\quad$ 26-Apr-2023 08:17:16
}

A navegação consulta e descarregamento dos títulos inseridos nas Bibliotecas Digitais UC Digitalis, UC Pombalina e UC Impactum, pressupõem a aceitação plena e sem reservas dos Termos e Condições de Uso destas Bibliotecas Digitais, disponíveis em https://digitalis.uc.pt/pt-pt/termos.

Conforme exposto nos referidos Termos e Condições de Uso, o descarregamento de títulos de acesso restrito requer uma licença válida de autorização devendo o utilizador aceder ao(s) documento(s) a partir de um endereço de IP da instituição detentora da supramencionada licença.

Ao utilizador é apenas permitido o descarregamento para uso pessoal, pelo que o emprego do(s) título(s) descarregado(s) para outro fim, designadamente comercial, carece de autorização do respetivo autor ou editor da obra.

Na medida em que todas as obras da UC Digitalis se encontram protegidas pelo Código do Direito de Autor e Direitos Conexos e demais legislação aplicável, toda a cópia, parcial ou total, deste documento, nos casos em que é legalmente admitida, deverá conter ou fazer-se acompanhar por este aviso.

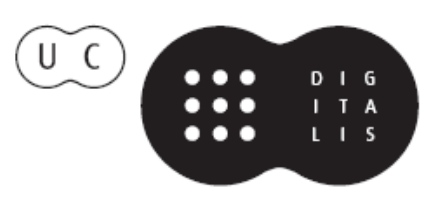




\section{ADVANCES IN}

Forest Fire

\section{RESEARCH}

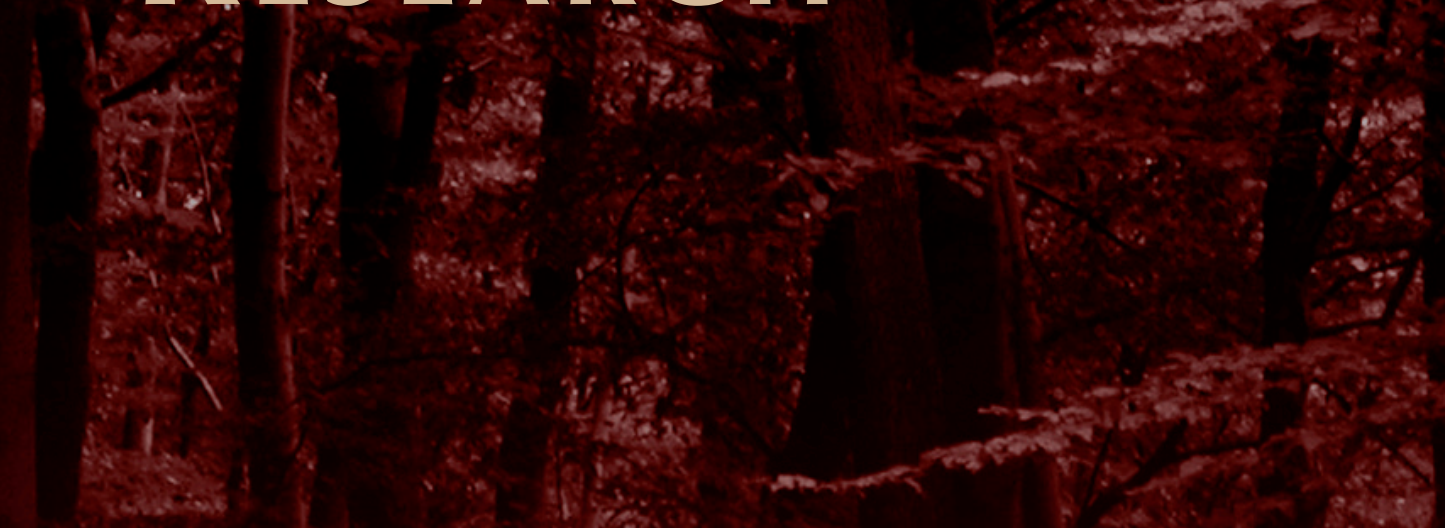

\section{DOMINGOS XAVIER VIEGAS}

\section{EDITOR}




\title{
Analysis of the jump fire produced by the interaction of two oblique fire fronts: Comparison between laboratory and field cases
}

\author{
Jorger Raposo ${ }^{\text {a. }}$ Domingos X. Viegas ${ }^{\mathrm{a}}$; Xiaodong Xie ${ }^{\mathrm{b}}$; Miguel Almeida ${ }^{\mathrm{a}}$. and Liu Naian ${ }^{2}$ \\ ${ }^{a}$ ADAI/CEIF, University of Coimbra, Rua Luís Reis dos Santos, Coimbra 3030-788, Portugal. \\ Jorge.raposo@dem.uc.pt. \\ ${ }^{b}$ State Key Laboratory of Fire Science, University of Science and Technology of China, Hefei, China
}

\begin{abstract}
The merging of two linear fire fronts intersecting at a small angle creates an accelerating fire that is designated as "jump fire", given the very high value of the rate of spread that it can reach in a relatively short time. In this work an analysis of the jump fire process based on laboratory scale, field scale experiments and large fire scale observation was performed. This confirmed that independently from the scale of analysis the fire in this condition follows the same behaviour pattern that is due to the fire geometry and to the associated heat transfer mechanisms that induce the phenomenon of a quick acceleration followed by a deceleration phase. $\mathrm{S}$ type pitot tubes were used to study the flow pattern inside or near the fire front to better understand the mechanisms of fire induced convection given its very important role in these fires.
\end{abstract}

Keywords: Forest fire behaviour; Jump fire; Merging fire; Dynamic effect; Extreme Fire

\section{Introduction}

The concept of "jump fire" behaviour associated to the merging of two linear fire fronts that intersect at a point making a small angle between them as was introduced in Viegas et al., $(2012,2013)$ with a conceptual model of energy release by the fire front, mainly by radiation was proposed to justify the very rapid decrease of a reference rate of spread (ROS) that was observed in laboratory scale tests performed with horizontal fuel beds. In the present study the previous work is extended to consider the effect of slope, various types of fuels, and different fire dimensions. A comparison of the results obtained at laboratory scale with the tests performed at field tests in the Lousã Mountain and also with the case of a very large forest-fire that occurred in Canberra in 2003 was made.

\section{Experimental Study}

\subsection{Physical problem}

We consider two linear fire fronts that intersect at point $D$ and making an angle $\theta_{\mathrm{o}}$ between them spreading on a uniform fuel bed making an angle $\alpha$ with the horizontal. The axis $O X$ is assumed to be a symmetry line of the fire (figure 1a)). Particular attention is given in this study to the displacement of the intersection point $D$ of the two fire lines that has a velocity or rate of spread $R$. In order to generalize our results we use the reference basic ROS $R_{o}$ of a linear fire front in the same fuel bed in the absence of slope or wind, to define the non-dimensional $\operatorname{ROS} R{ }^{\prime}=R / R_{o}$. 


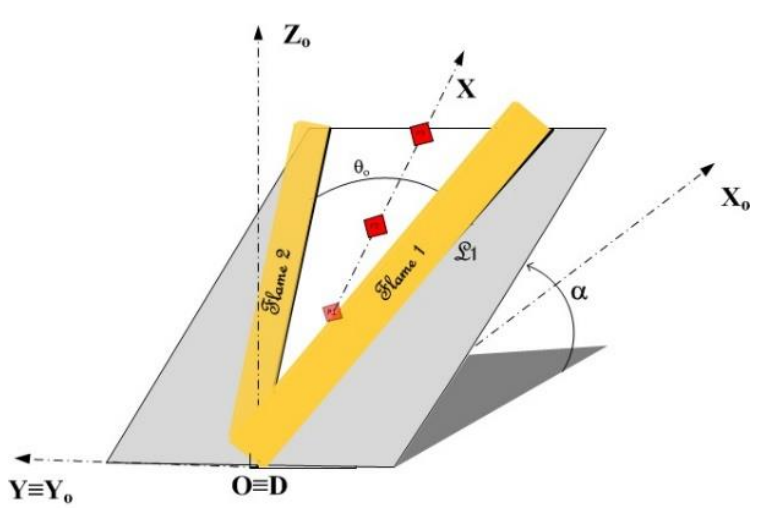

a)

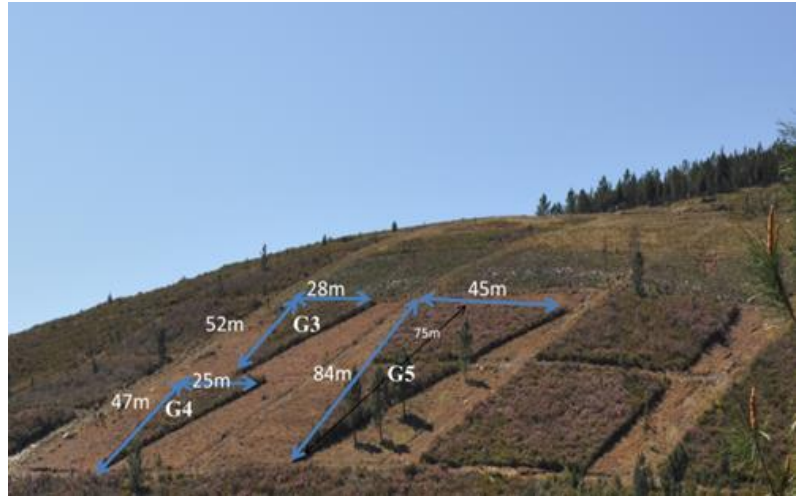

b)

Figure 1. a) Schematic representation of the problem. b) View of the plots burned at the field tests of jump-fire in Gestosa.

The configuration of the fuelbed is shown in figure 1 schematically for the laboratory and for the field tests respectively. In all tests the fuelbed had a triangular shape with an angle $\theta_{0}=30^{\circ}$ and the fire front was initiated along the two large sides of the triangle (indicated as Flame 1 and Flame 2 in figure 1a). A large set of tests on the scope of jump fires was performed both at laboratory and at field scale. From these tests some were selected for the present work including a case study of the Canberra 2003 fire. The main parameters of the cases that are considered in this paper are given in Table 1.

Table1: Parameter of jump-fire cases considered in the present study

\begin{tabular}{ccccc} 
Designation & Fuel & $\boldsymbol{\alpha}$ & Scale & Series \\
\hline CF02 & PP & 40 & Lab & S1 \\
CF05 & PP & 0 & Lab & S1 \\
CF07 & PP & 10 & Lab & S1 \\
CF14 & PP & 20 & Lab & s2 \\
CF15 & PP & 20 & Lab & s2 \\
CF17 & PP & 30 & Lab & s2 \\
CF44 & PP & 20 & Lab & s5 \\
CF54 & PP & 30 & Lab & s5 \\
CF55 & PP & 0 & Lab & s5 \\
CF57 & SH & 30 & Field & - \\
CF59 & SH & 30 & Field & - \\
CF60 & SH & - & Canberra & - \\
& & & 2003 &
\end{tabular}

\subsection{Laboratory Experiments}

Laboratory experiments were carried out at the Forest Fire Research Laboratory of the University of Coimbra using the table DE4 that has a useful area of $6 \times 8 \mathrm{~m}^{2}$ with a slope $(\alpha)$ that can be varied in the range of $0^{\circ}$ to $40^{\circ}$.

The methodology used is similar to the one described in Viegas et al. (2013) with the addition of flow velocity measurements using $\mathrm{S}$ type pitot tubes placed along $\mathrm{OX}$ axis at 1,3 and $6 \mathrm{~m}$ from point $D$ as indicated in figure 1a). The measured properties were temperature, pressure and heat flux. The measurement of the temperature was made with a multi-point system of $25 \mathrm{~K}$ type thermocouples, connected to a NI cDAQ-9174 that allows a synchronous data-logging. This 25 thermocouples (TC) were placed in a beam coincident with the OX axis. The position of each thermocouple is known and the gap between thermocouples is constant of $20 \mathrm{~cm}$ the rate of acquisition was of $1 \mathrm{~Hz}$. For a spatial 
distribution of the temperature along the fuel-bed infrared images from each experiment were recorded, using an infra-red camera FLIR ThermaCam SC640 The acquisition rate was also 1Hz. In both methods the presence of the fire front was considered for values of temperature above $350^{\circ} \mathrm{C}$ that was considered as sign of the existence of flame in the place or time of measurement. Using IR methodology the position of the fire perimeter at given time frames was assessed and from these images the ROS at various positions of the fire perimeter namely at point $\mathrm{D}$ were measured. Using the thermocouples and knowing time interval required for the fire to travel from one position to the next the ROS of the fire along OX axis was measured as well. Besides this all the tests were recorded by a Sony high definition video camera and temporized shots were also taken with a Cannon photographic high performance digital camera.

The flow velocity was measured at three different points along $\mathrm{OX}$ axis at $1 \mathrm{~m}, 3 \mathrm{~m}$ and $6 \mathrm{~m}$ from the origin, with pitot tubes designated respectively P1, P2 and P3. The pitot tubes used were type S specially designed for the purpose as they are indicate to perform measurements inside dirty and high temperature flows. The pitot were placed along the centre line at the high of $15 \mathrm{~cm}$ from the ground so that the pitot was always above the fuel bed but inside the flame zone. Each pitot was connect by pipes to a differential pressure transducer Gems 5266-50L Very Low Range Differential Pressure Transmitter. These transducers were connect to a multifunctional NI 6009-DAQ that made the datalogging of the signal also with a frequency of $1 \mathrm{~Hz}$. With the data collected by this method using the values of synchronous temperature measurements by the application of a calibration it was possible to estimate the flow velocity induced by the fire phenomena.

\subsection{Field Experiments}

The field tests were performed in Gestosa, Lousã, with $V$ shaped plots with dimensions indicated in figure $1 \mathrm{~b}$ ). The plots were prepared cutting shrub vegetation with height varying between 0.5 and $1.2 \mathrm{~m}$ using mechanical tools in order to give the plots the desired shape. The average slope of these plots is $30^{\circ}$ and the initial angle between the fire fronts was $30^{\circ}$. In order to assure a simultaneous ignition of the two fire lines along their entire length pyrotechnics devices were used. Due to the presence of lateral wind during the experiments full symmetrical conditions were not obtained. During these tests infrared and visible range images were recorded to allow fire spread analysis. Thermocouples were disposed along the central axis of the plots to measure the temperature evolution and consequently the rate of spread in the centre line as in the laboratory experiments. The real case occurred during the merging if two large fires in the vicinity of Canberra in January 2003, that are documented in Doogan (2006), creating a very intense jump-fire phenomenon. In mid-afternoon of the $18^{\text {th }}$ January 2003 the flanks of Bendora and McIntyres large fires merged on undulating ground covered by grass, shrubs and groups of tress under a strong wind of the order of $25 \mathrm{~m} / \mathrm{s}$. The merging of these fires developed very rapidly towards Canberra and even produced a tornado near one of its flanks. More details on this fire can be found in Sharples et al., (2012).

\section{Results and Discussion}

\subsection{Effect of fuel bed slope}

In Figure 2 the dimensional rate of spread ROS for three different slope angles $0^{\circ}, 20^{\circ}, 30^{\circ}$ and $40^{\circ}$ with fuel bed of dead pine needles of Pinus pinaster is plotted as function of time t. As it is typical for the jump fire phenomena these tests show a pattern of behaviour that involves a sharp acceleration in its initial phase until the peak velocity is reached and afterwards it decreases reaching relatively low values.

The analysis will be mainly focused in speeding up phase of the fires. The deceleration phase was already considered in Viegas et al. (2012) but needs to be more investigated. Although some observations and comments on this phase are made here its more detailed analysis will be the scope of future work. 
As can be seen in figure 2 for $\alpha=0^{\circ}$ the acceleration phase lasts less than two seconds and therefore it is not captured with the experimental methodology that was used. For $\alpha=20^{\circ}$ this phase lasts about 12 seconds and therefore can be clearly picked up in our laboratory experiments. The same happens for $\alpha=30^{\circ}$ and $40^{\circ}$ for which the acceleration phase takes about 22.5 and 15.1 seconds respectively. The peak ROS value also increases with slope angle. In these tests the following maximum ROS values were observed: $7.7 \mathrm{~cm} / \mathrm{s}, 15.4 \mathrm{~cm} / \mathrm{s}, 22.5 \mathrm{~cm} / \mathrm{s}$ and $39.4 \mathrm{~cm} / \mathrm{s}$ for $\alpha=0^{\circ}, 20^{\circ}, 30^{\circ}$ and $40^{\circ}$ respectively. It is interesting to notice that on the contrary the deceleration phase duration decreases with slope angle except for the case of $\alpha=40^{\circ}$ here no deceleration phase was recorded. In these experiments the following values were registered for the duration of the deceleration phase: 300s, $60 \mathrm{~s}$ and $5 \mathrm{~s}$ for $\alpha=0^{\circ}$, $20^{\circ}$ or $30^{\circ}$ respectively.

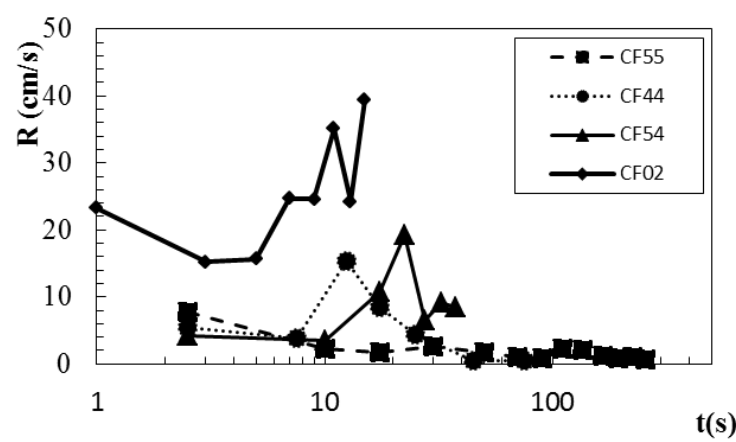

\section{Figure 2. Plot of the Dimensional rate of spread $R$ as function of time t for three different slope angles $0^{\circ} ; 20^{\circ} 30^{\circ}$ and $40^{\circ}$ with fuels}

The change of jump fire behaviour from an accelerating ROS to a deceleration indicates that this phenomenon is based on the shifting of the main physic heat transfer processes of convection and radiation. Convective flows generated by the interaction of the fire fronts that are developed during the fire front evolution play a major role in the acceleration phase but there seems to be an opposing effect due both to convection and radiation (associated to the change of flame geometry) that stops the acceleration phase and produces the deceleration phase that seems to be mostly related to this change of flame geometry.

\subsection{Analysis of the fire acceleration phase}

The phase of sharp acceleration can be interpreted at the light of the concept of dynamic fire behaviour due to the feedback between the fire and its surrounding flow proposed in the model to predict eruptive fires presented in Viegas (2006). According to this model the time involved in the acceleration of a pint source fire front in a slope or canyon is associated to a characteristic time of each fuel bed. This time is related to the residence time of the combustion in the fuel bed and therefore it is large for heavier fuels. The special configuration of the jump fire create similar effects due to the heat transfer processes associated to the phenomena particularly to the role of convection in this phase. In spite of this similarity it was realised that contrary to eruptive fires in jump fires the increasing phase has a limit of growth.

In order to better interpret the problem the use non-dimensional parameters based on selected reference parameters is adopted. This method is also required to overcome the problem of scale and allows the application of results of laboratory scale tests to full size experiments or even to real fires with much larger dimensions.

To describe the evolution of ROS in the course of time the non-dimensional parameters $R$ ' and $t$ ' were used to present the results of both laboratory and field scale tests in figure 3 . The non-dimensional value of $t^{\prime}=t / t_{\mathrm{o}}$ was evaluated following Viegas (2006) the residence time $t_{\mathrm{o}}$ that was measured in our tests were used. These values are given in Table 2. 
Table2: Characteristic Residence time for the different fuels

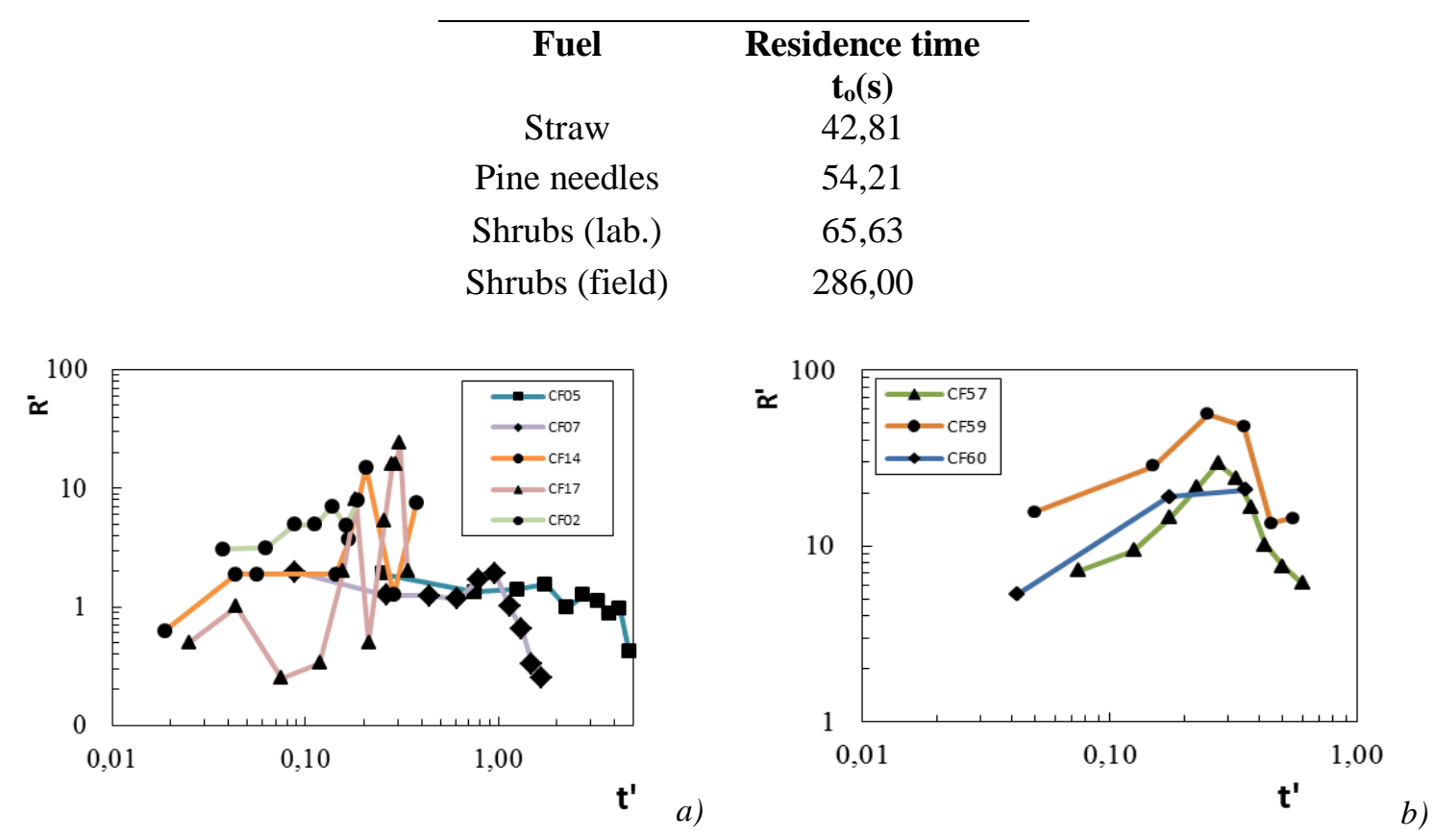

Figure 3. Evolution of non-dimensional rate of spread $R$ ' as function of the reference time t', for laboratorial tests a), field tests and the case of Canberra, Australia b).

In figure 3 a) the values of $R^{\prime}$ for a set of laboratory experiments with Pinus pinaster needles were plotted as a function of $t^{\prime}$ for slope angle values of $0^{\circ}, 10^{\circ}, 20^{\circ}, 30^{\circ}$ and $40^{\circ}$, although this is not the same set of tests of figure 2 they are in agreement with the previous set. The peak values of $R^{\prime}$ are in the range between 3 and 25. The accelerating phase can be clearly observed in these tests for values of $\mathrm{t}^{\prime}<0.3$. The same trend that was referred above can be observed here: while for the case of $\alpha=0^{\circ}$ the accelerating phase was not observed in the case of $\alpha=40^{\circ}$ the deceleration phase is non-existent.

In figure $3 \mathrm{~b}$ ) the corresponding results for two field tests and for the Canberra fire are shown. The similarity between figures $3 \mathrm{a}$ ) and $3 \mathrm{~b}$ ) is quite apparent in spite of the scales of the tests. The similarity can be observed both in the general form of the curves but also in the order of magnitude of the reference parameters like for example the peak values of $R^{\prime}$ and of the corresponding values of $t$ '.

\subsection{Flow analysis}

In order to better assess and understand the role of convection induced by the fire during the speeding up process, results of sample flow velocity measurements are presented.

In figure 4 the horizontal flow velocity $U(\mathrm{~m} / \mathrm{s})$ close to the fuel bed measured at each station is plotted as a function of the distance $x$ - $x_{p}$ of the fire front to the corresponding sensor for three values of slope angle. These figures put in evidence the complexity of the flow associated to fire evolution and of the rapidly changing character of the induced flow near the fire front. We observe periods of negative flow velocity (flow in the negative direction of OX axis), followed by periods of positive velocity. The negative flow velocity acts as a counter flow in relation to flame spread and it may explain the fact that the acceleration phase is limited. The positive or inflow flow velocity is observed mainly after the passage of the fire front and it is an indication of fire acceleration. This is more clearly observed in figure a c) for $\alpha=30^{\circ}$. In this case it is interesting to see that at pitot P1 placed $1 \mathrm{~m}$ above the origin of $\mathrm{OX}$ axis the flow is negative after the passage of the fire and then reaches a very high positive peak, corresponding to the acceleration of the fire along the slope while at pitot P2 $(x=3 \mathrm{~m})$ the flow is positive even before the fire reaches the pitot station. 
The peak of the inflow velocity increases with $\alpha$ in correspondence to the increase of the maximum value of ROS.

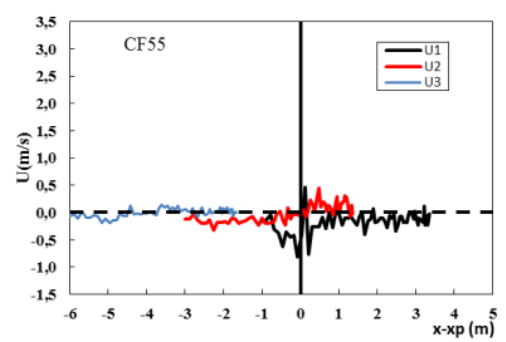

a)

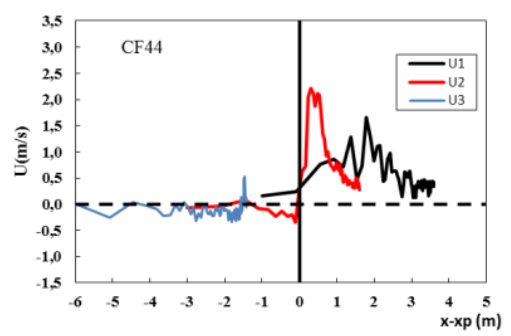

b)

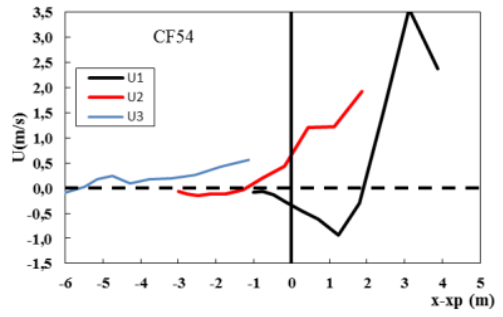

c)

Figure 4. Flow speed $U$ measured at three differents points along the center line placed at $1 m(U 1), 3 m(U 2)$ and $6 m$ (U3) from point $D$, for three different slope angles a) $0^{\circ}$; b) $20^{\circ}$ and c) $30^{\circ}$.

\title{
4. Conclusion
}

Analysis of the jump fire process based on laboratory scale, field scale experiments and large fire scale observation shows that in all cases the fire follows the same behaviour pattern that is due to the fire geometry characteristics of two convergent fire lines and to the associated heat transfer mechanisms that induce the phenomenon that is designated as jump-fire.

Taking into account the data presented it is possible to realize that the patterns of behaviour of the jump fires are very much dependent on the convective flows generated by this special way of burn. The complex geometry of jump fires give origin to unstable boundary conditions that will dynamically affect the fire spread both by convective flows and by radiative heat transfer processes that are greatly affected by morphisms in the fire fronts that occur in this phenomena in the course of time.

The $\mathrm{S}$ type pitot tubes appeared as important tools to analyse the flow pattern inside or near the fire front contributing to a better understanding of the mechanisms of this phenomenon given the very important role played by induced convection in these fires.

More research is necessary to be able to model the complex heat and mass transfer processes during a jump fire for arbitrary fuel and boundary conditions. The authors will develop an effort towards producing such a model to explain and predict the two phases of jump-fires.

\section{Acknowledgments}

The authors wish to thank Portuguese Science Foundation for the support given to project Extreme under contract PTDC/EME-MFE/114343/2009 and for a PhD grant under contract SFRH / BD / 85557 / 2012. The participation of Naian Liu and Xiaodong Xie were supported by the bilateral project of cooperation between Portugal and China founded by the Portuguese Science Foundation.

The authors thank their colleagues who supported the experimental work in laboratory and in the field experiments, namely Ricardo Oliveira, Nuno Luís and Luís Ribeiro.

\section{Symbology}

$\begin{array}{cc}\text { Symbol } & \text { Units } \\ \alpha & - \\ \theta & - \\ \mathrm{O} & - \\ \mathrm{D} & -\end{array}$

\author{
Description \\ Inclination angle \\ Angle between the fire fronts \\ Origin of reference Cartesian system \\ Intersection point $\mathrm{D}$ of the two fire lines
}

Advances in Forest Fire Research - Page 93 


$\begin{array}{ccc}\text { X } & - & \text { Coordinate along reference OX axis } \\ \text { Xo } & - & \text { coordinate along reference horizontal axis OXo } \\ \text { Y } & - & \text { coordinate along reference OY axis } \\ \text { Yo } & - & \text { coordinate along reference horizontal axis OYo } \\ \text { Zo } & - & \text { coordinate along reference horizontal axis OZo } \\ \mathcal{L}_{1} & - & \text { Fire line 1 } \\ \mathcal{L}_{2} & - & \text { Fire line 2 } \\ R & c m \cdot s^{-1} & \text { Rate of spread (ROS) } \\ R_{o} & c m \cdot s^{-1} & \text { Basic rate of spread of linear fire in the absence of slope and wind } \\ R^{\prime} & - & \text { Non-dimensional rate of spread (NDROS) } \\ U_{1} & m \cdot s^{-1} & \text { Flow velocity measured by Pitot 1 } \\ U_{2} & m \cdot s^{-1} & \text { Flow velocity measured by Pitot 2 } \\ U_{3} & m \cdot s^{-1} & \text { Flow velocity measured by Pitot 3 } \\ t_{o} & s & \text { Residence time } \\ t & - & \text { Reference time } \\ P 1 & - & \text { Pitot station 1 } \\ P 2 & - & \text { Pitot station 2 } \\ P 3 & - & \text { Pitot station 3 } \\ \text { PP } & - & \text { Fuelbed of Pinus pinaster dead needles } \\ \text { SH } & - & \text { Fuelbed of dead shrubs } \\ \text { IR } & - & \text { Infrared image } \\ \text { TC } & - & \text { Thermocouple }\end{array}$

\section{References}

Doogan M. 2006. Inquests and Inquiry into Four Deaths and Four Fires between 8 and 18 January 2003. (ACT Coroner's Court: Canberra, ACT)

Viegas, D., Raposo, J. and Figueiredo, A. R. 2013. Preliminary analysis of slope and fuel bed effect on jump fire behavior in forest fires. Procedia Engineering. Volume 62, pp. 1032-1039.

Viegas, D., Raposo, J., Davim, D. and Rossa, C. 2012. Study of the Jump Fire Produced by the Interaction of Two Oblique Fire Fronts. Part 2: Analytical Extended Model and Validation with Slope Laboratory Experiments. International Journal of Wildland Fire. 21, 843-856

Viegas, D. 2006. Parametric study of an eruptive fire behavior model. International Journal of Wildland Fire, Volume 15(2), pp. 169-177.

Sharples, J., McRae, R.H.D., and Wilkes, S.R. (2012). "Wind-terrain effects on the propagation of wildfires in rugged terrain: fire channelling." International Journal of Wildland Fire 21, 282-296. 